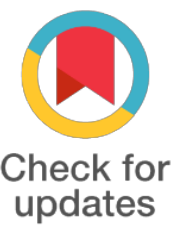

Check fo
updates

(n)
*For correspondence:

saintispath@gmail.com

Competing interests: The authors declare that no competing interests exist.

Received: 2017-07-11

Accepted: 2017-08-18

Published: 2017-09-05

Copyright The Author(s) 2017. This article is published with open access by BioMedPress (BMP).

This article is distributed under the terms of the Creative Commons Attribution License (CC-BY 4.0) which permits any use, distribution, and reproduction in any medium, provided the original author(s) and the source are credited.

\section{THE ROLE OF THE CASPASE FAMILY in PF4- INDUCED APOPTOSIS IN BREAST CANCER IN VIVO STUDY}

ORAL

\author{
Tengku Ahmad Damitri Al Astani Tengku Din, Azman Seeni, Muhammad Irfan \\ Abdul Jalal, Muhamad Saiful Bahri Yusoff, Shaharum Shamsuddin, Hasnan Jaafar
}

School of Medical Sciences, Universiti Sains Malaysia, Health Campus Universiti Sains Malaysia

\section{Abstract}

Background: Apoptosis is critical to the development and homeostasis of metazoans. Apoptotic dysregulation leads to various human pathologies including cancer, autoimmune and neurodegenerative disorders. Caspases, sub-members of cysteine proteases, are the central components of apoptotic response. The ELR-negative chemokine platelet factor 4 (PF4) was initially identified as an antiangiogenic agent. It inhibits endothelial cell proliferation, migration and angiogenesis in in vitro and in vivo and was further proving in the in vivo models of human colon carcinoma and murine melanoma xenograft mouse. However, there are no studies (either in-vivo or ex-vivo) which have conclusively demonstrated and characterized the PF4 effects on inducing apoptosis in breast cancer setting and therefore, this becomes the study's central objective.

Aim: This study aimed to investigate PF4's effects on the apoptosis regulation mediated by caspase $-3,-6,-7,-8$ and -9 in 1-methyl-1-nitrosourea-induced (MNU) invasive murine breast carcinoma model.

Methods: Breast carcinoma were induced in 60, 21 -day-old female Sprague Dawley Rat (SDR) using 1-methyl-1-nitrosourea until its size reached $14.5 \pm 0.5 \mathrm{~mm}$. The tumors were divided into two groups: Group 1 (control pre-treated, $n=20$ and post treated, $n=20$ ), and Group 2 (PF4, $n=20$ ). PF4 were administered through focal intralesional injections at $20 \mu \mathrm{g} /$ lesion dosage. After 5 days of treatment, the SDRs were sacrificed. Subsequently the tumor specimens were prepared for haematoxylin and eosin staining. The expression of caspases family members (caspase-3,-6,-7,-8 and-9) were detected using immunohistochemistry. The specimens were morphologically examined and the cell counts with positive caspases expressions were recorded.

Results: There was a significant reduction of tumor size after PF4 treatment compared to the controls. PF4 demonstrated differential effects on downstream effector caspases; both upregulated caspase -3 and -6 , and downregulated caspase-7 expression was observed compared to controls. PF4 exhibited significant effects on the three caspases-3, -6 and -7 ( $p<0.001, p=0.004$ and $p=0.024$, respectively). PF4 had no effect on caspase- $8(p=0.067)$ and caspase $-9(p=0.061)$ expressions.

Conclusion: This study found that PF4 significantly reduced the tumor sizes in a short time (less than 3 days) and acts differentially on the caspase-mediated apoptosis pathways and on the downstream levels of the apoptotic machinery.

\section{Keywords}

Breast cancer, apoptosis, PF4, caspase 
Funding

\section{References}

1- Guicciardi ME, Gores GJ. Unshackling caspase-7 for therapy. J.Clinical Investigation. 2013; 1 23(9):3706-3708.

2- Cui Q, Yu JH, Wu J, Tashiro S, Onodera S, Minami $M$ and Ikejima T. P53-mediated cell cycle arrest and apoptosis through a caspase-3-independent, but caspase-9-dependent pathway in oridonin-treated MCF-7 human breast cancer cells. Acta Pharmacologica Sinica 2007;28(7):10571066.

3- Vakkala, M., Pääkkö, P. and Soini, Y., 1999. Expression of caspases 3, 6 and 8 is increased in parallel with apoptosis and histological aggressiveness of the breast lesion. British journal of cancer, 81 (4), p.592.

4- Ruiz-Ruiz C, Munoz-Pinedo C, Lopez-Rivas A. Interferon- $\gamma$ treatment elevates caspase-8 expression and sensitizes human breast tumor cells to death-receptor-induced mitochondriaoperated apoptotic program. Cancer Research 2000;60(20):5673-5680.) 